\title{
Microphthalmos with colobomatous orbital cyst: clinical, histological, immunohistological, and electronmicroscopic findings
}

\author{
W Lieb, R Rochels, U Gronemeyer
}

\begin{abstract}
A case of unilateral microphthalmos with orbital cyst is presented. This rare and severe malformation is a non-hereditary disorder. Pathologically it represents a failure in the closure of the embryonic fissure at the 7-14 mm stage of gestation. Staining for neurofilaments permitted the identification of rudimentary optic nerve fibres within the gliomatous cyst wall. Special stains for glial fibrillary acidic protein as well as scanning and transmission electron microscopy were used to characterise the neuroglial cell lining of the cyst wall, and to show microvilli on its inner surface.
\end{abstract}

Numerous case reports can be found on microphthalmos and orbital cyst. ${ }^{1-12}$ This nevertheless rare entity is defined as a cystic mass lined by neuroectoderm protruding through a coloboma of a microphthalmic eye. It appears usually during the first few months after birth and is usually unilateral, though bilateral cases have been described. ${ }^{13}$ There is no sex prevalence and in contrast to a similar malformation in animals the majority of cases are non-hereditary ${ }^{14}$ and not associated with other malformations. Some associated other findings have been described. ${ }^{15}$ There is even a report of an astrocytoma of the optic nerve arising in a case of microphthalmos and orbital cyst.

Although it is a clearly defined entity, many of these lesions are still misdiagnosed for an orbital tumour. Clinical examination is in most of the cases the key to making the diagnosis. Nowadays imaging techniques as $\mathbf{A}$ and $\mathbf{B}$ scan ultrasonography,${ }^{16}$ computed tomography,${ }^{17}$ and magnetic resonance imaging ${ }^{15}$ are helpful in supporting the diagnosis and in differentiating it from a congenital cystic eye, ${ }^{18}$ meningocele, or meningoencephalocele, primary optic nerve sheath cysts, ${ }^{13}$ and teratomas of the orbit. Orbital teratomas quite often have a cystic appearance and are usually benign, though malignant changes have been reported. ${ }^{19}$

In our case we had the opportunity to use immunohistochemical techniques as well as scanning and transmission electron microscopy to study this unusual lesion.

\section{Case report}

A 1-month-old white female child was referred with the diagnosis of a right orbital mass. The child was the product of a normal pregnancy and labour. Her general health as well as her sensory and motor development were normal.

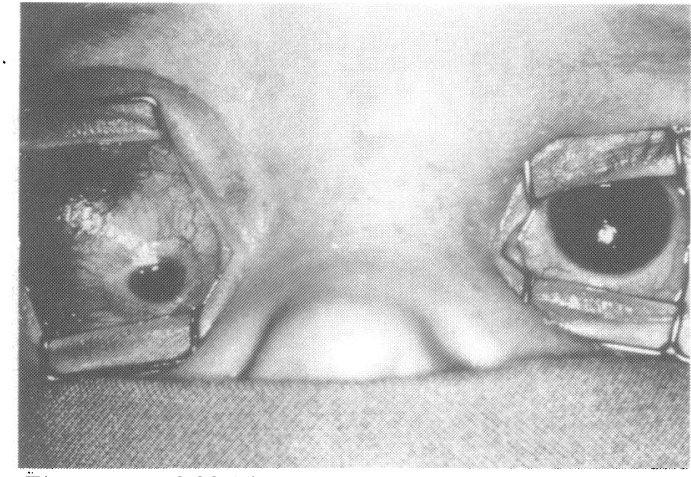

Figure 1: Dark bluish mass involving the superotemporal part of the right orbit. The microphthalmic globe is displaced inferonasally.

Since birth the parents had noticed a slowly progressive protrusion of the right globe. A general paediatric examination revealed a normally developed otherwise healthy child.

On ophthalmological examination the child did not fixate with the right eye and there was a superficially vascularised mass occupying the superotemporal part of the orbit, which, except for a small globe rudiment inferonasally, transilluminated. The microphthalmic globe, measuring approximately $8 \mathrm{~mm}$ in diameter (Fig 1), had a diffusely clouded cornea. An iris coloboma was suspected, and there was a white vascularised membrane in the pupil. The left eye was entirely normal.

A and B scan ultrasonography (Digital B, Cooper Vision, and 7200 MA Kretztechnik) was performed and showed a small globe filled with medium to highly reflective tissue, and there was a large cystic structure attached to the globe occupying most or the orbit. The clinical diagnosis of a microphthalmos and orbital cyst was made and confirmed by magnetic resonance

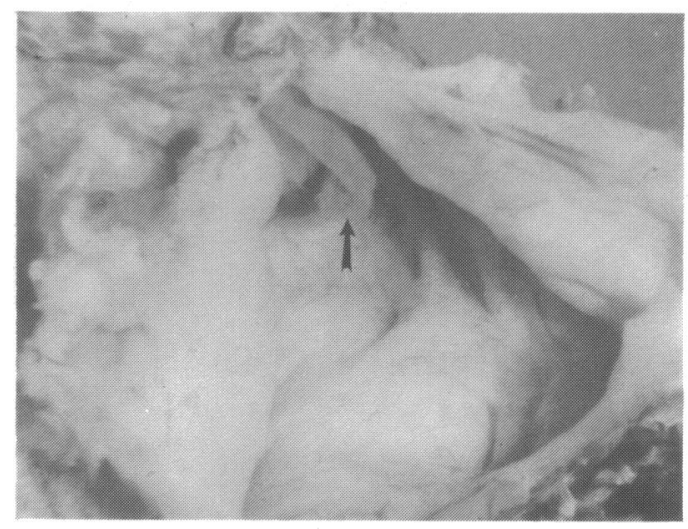

Figure 2: Macroscopic view from behind into the orbital cyst. At the transition of the microphthalmic eye into the cyst (arrow) an opaque delicate tissue is visible which represents the dysplastic retina. 


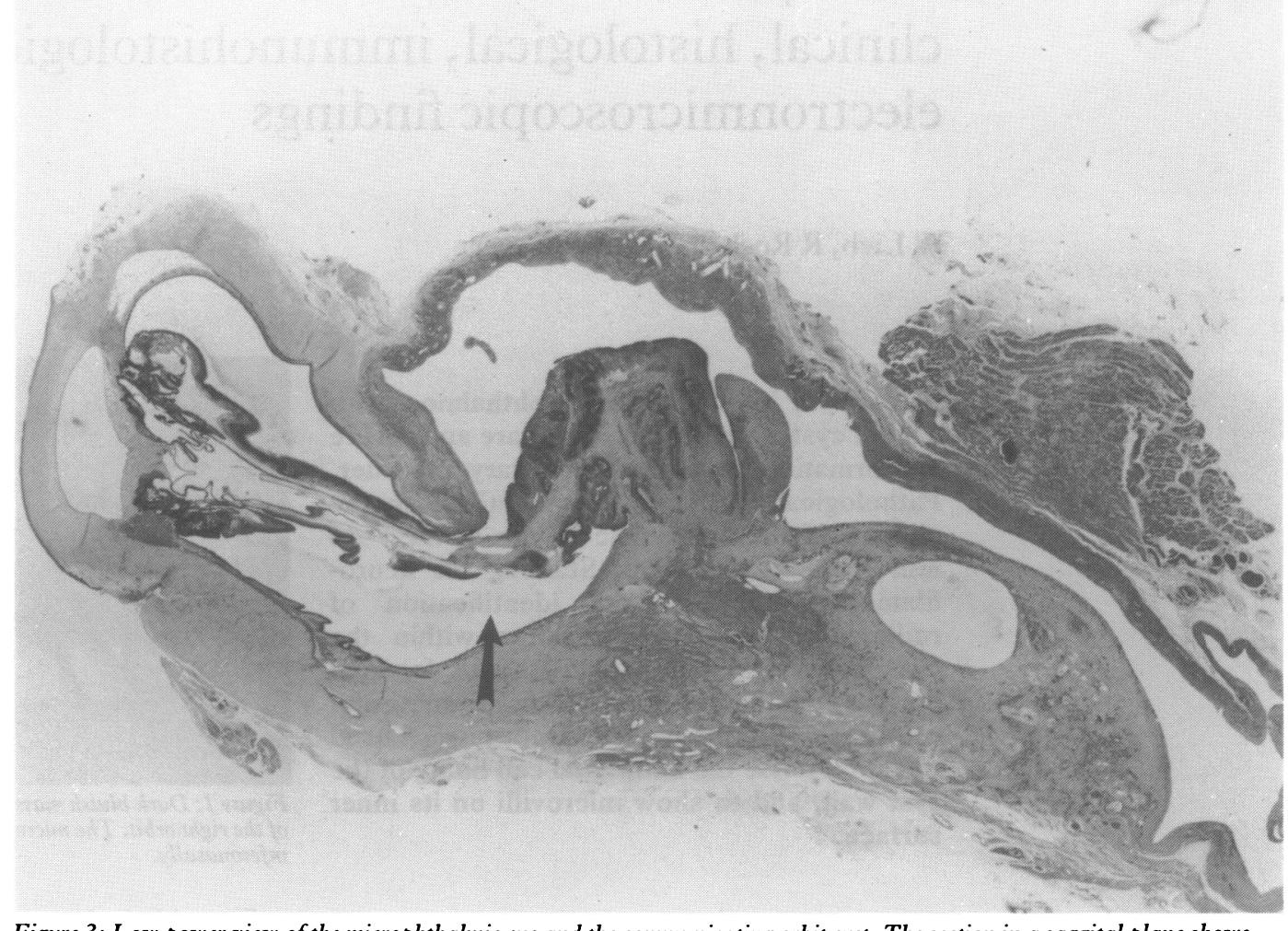

Figure 3: Low power view of the microphthalmic eye and the communicating orbit cyst. The section in a saggital plane shows clearly the colobomatous defect (arrow) and the dysplastic retina attached to a gliomatous mass in the cyst wall. (H and $E, \times 20$.)

imaging (MRI) and orbital computed tomography (CT).

On the parents' request the grossly malformed

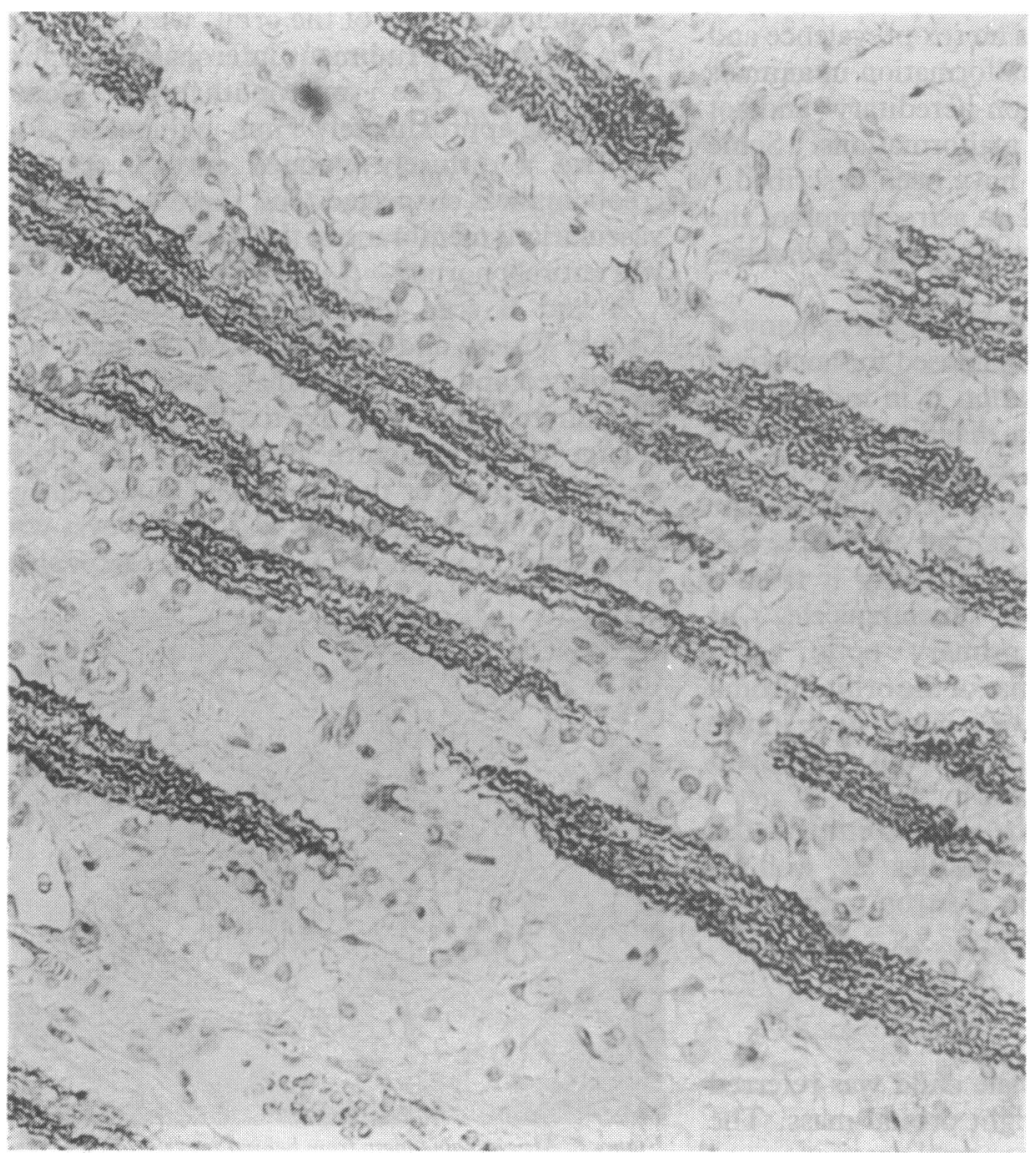

Figure 4: Stains for neurofilaments demonstrate optic nerve fibrils within the cyst wall in the area where the gliomatous dysplastic retina inserts into the gliomatous mass.

(Immunoperoxidase stain, $\times 50$.) blind eye was enucleated. The enucleation and removal of the orbital cyst was uneventful. However, since the cyst reached up to the orbital apex, it was impossible to remove the furthest posterior part of it.

\section{PATHOLOGY}

Macroscopic examination revealed a $17 \cdot 5 \times 16$ $\times 18 \mathrm{~mm}$ large collapsed cystic mass. In its inferionasal part was a $11 \times 10 \times 9 \mathrm{~mm}$ globe. The small globe as well as a solid hard structure in the nasal wall of the cyst did not transilluminate. At the transition from the globe to the cyst an opaque fine tissue was visible (Fig 2). The specimen was cut in a sagittal plane (Fig 3 ) and processed in serial sections.

Microscopic sections showed a moderately thickened stratified squamous epithelium of the cornea; Bowman's layer was absent; the corneal stroma was still rather cellular; the endothelial cell count was normal, but the endothelial cells had a vacuolar cytoplasm. The endothelium covered the anterior aspect of the chamber angle structures. The trabecular meshwork and Schlemm's canal were not yet differentiated. On the posterior iris surface elongated ciliary processes were seen, which were connected to a dysplastic retina with malformed rosettes. In between the folded retina there were remnants of the lens epithelium and posterior lens capsule, with only few particles of cortex material. Remnants of the anterior and posterior tunica vasculosa of the lens could be seen.

The inner surface of the microphthalmic globe was covered by pigment epithelial cells. The dysplastic retina was folded and reached through a large defect in the posterior wall of the globe into the large orbital cyst (Fig 3 ). Here the folded 


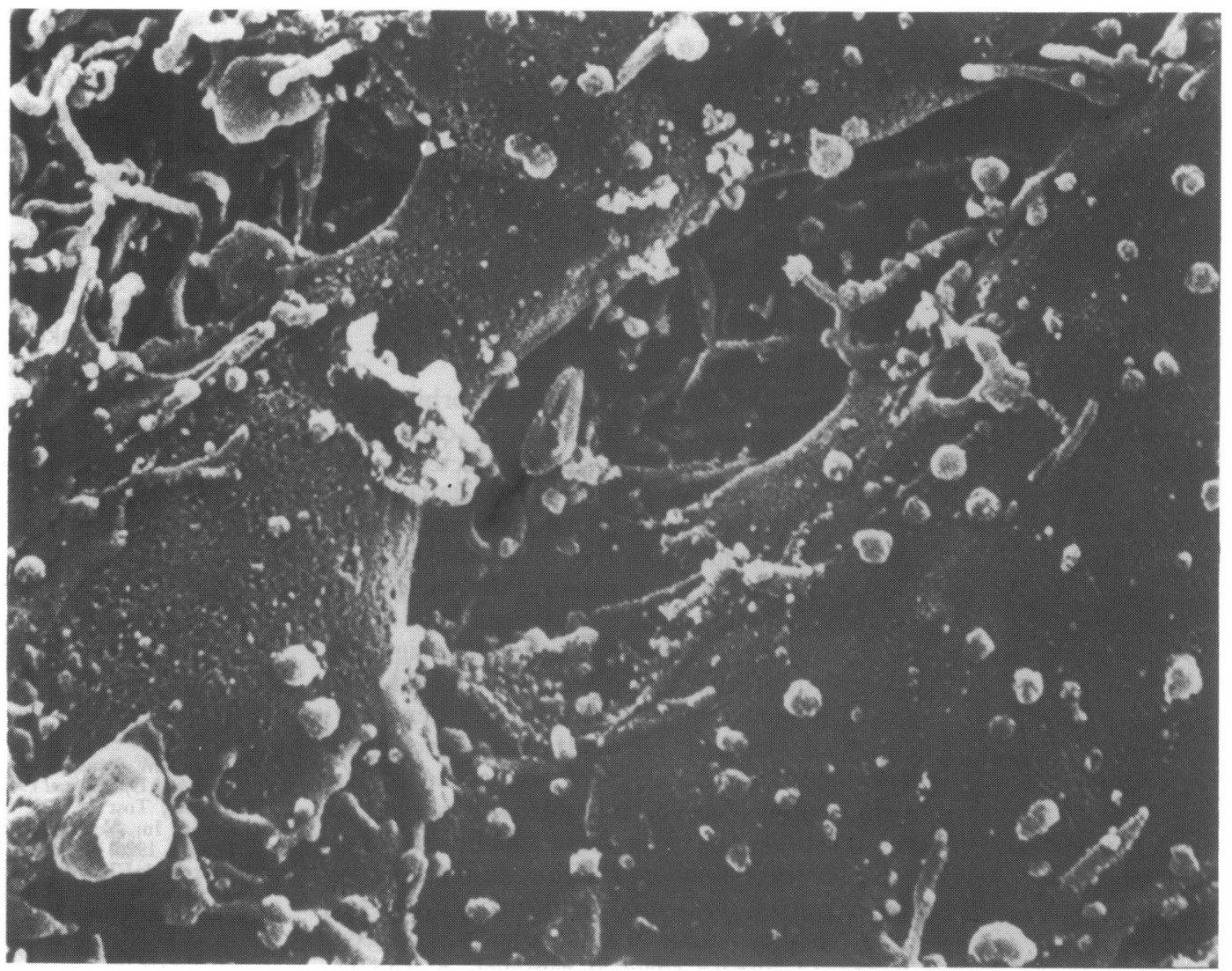

Figure 5: Scanning electron microscopy of the inner cyst wall. There are numerous layers of flat glial cells with microvilli on the cell surface. $(\times 10400$. $)$

retina was connected to a mass of glial tissue extending into the cyst lumen. Choroid, Bruch's membrane, and the retinal pigment epithelium extended through the coloboma but ended abruptely a short distance into the cyst. The thick scleral tissue continued to cover the orbital cyst, whose inner wall was lined by a thick layer of highly vascularised glial tissue. On the posterior aspect of the cyst skeletal muscle fibres and adipose tissue could be identified. To define the inner lining of the cyst better we stained for glial fibrillary acidic protein (GFAP), which stain diffusely the inner cyst wall. In addition the glial elements of the dysplastic retina were stained. GFAP is the major intermediate filament subunit in the mature astrocytes.

Since remnants of optic nerve tissue could not be found on routine histological examination, we stained for neurofilaments. These showed as fine fibrillary structures in the nasal cyst wall deep to the glial mass connecting to the retina (Fig 4). The neurofilament protein consisted of three

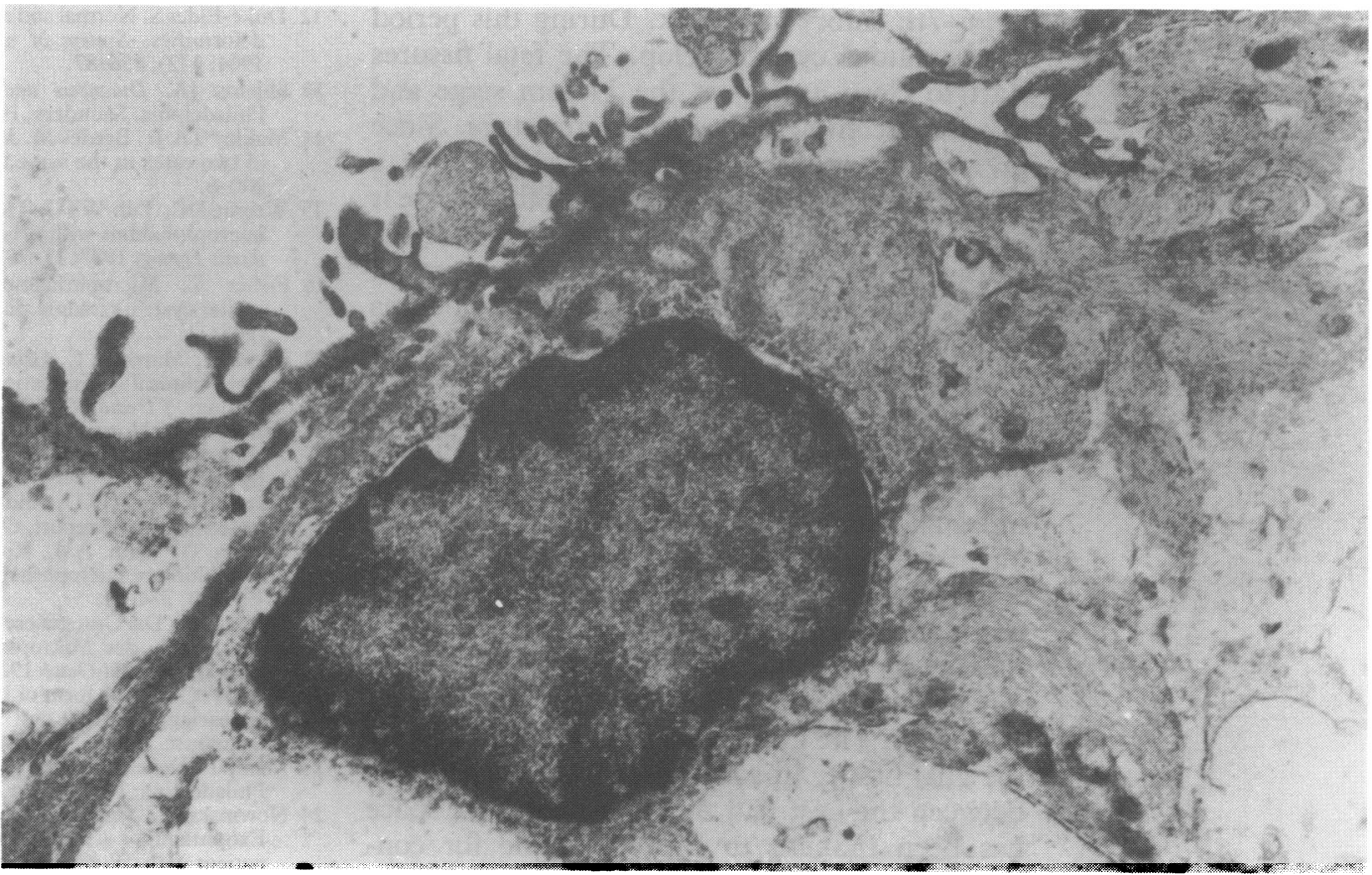

Figure 6: Transmission electron microscopy shows the fine microvilli lining the glial cells toward the cyst lumen. $(\times 14000$. $)$ 
polypeptides ranging in their molecular weight from 70 to $200 \mathrm{~K}$.

Scanning electron microscopy of the inner cyst wall showed flat cells in several layers with multiple button-like excrescences on their surface (Fig 5). Transmission electron microscopy identified clearly these structures seen on scanning EM as fine microvilli at the surface of the glial cells (Fig 6)

\section{Discussion}

Microphthalmos with colobomatous orbital cyst is a rare differential diagnosis of congenital orbital tumours. ${ }^{12}{ }^{13}$ It is usually detected in the early neonate period. The typical presentation is a protruding mass in the inferior orbit associated with an often quite severely malformed microphthalmic eye. In some instances the eye cannot be identified clinically ${ }^{20}$; the globe may be completely surrounded by the cyst, or there might be a very rudimentary displaced microphthalmic eye. Colobomatous orbital cysts are generally unilateral, though bilateral cases have been described. ${ }^{13} \mathrm{~A}$ number of associated other malformations have been reported. However, as in our case, it may be an isolated malformation.

So far there is no convincing evidence of an underlying chromosomal abnormality. Whereas in earlier times many of these lesions have been diagnosed during surgical removal, nowadays this entity is recognised clinically. The various imaging techniques - A and B scan ultrasonography, ${ }^{15}$ computed tomography,${ }^{16}$ and magnetic resonance imaging ${ }^{14}$ - enable us to differentiate this entity more easily from other benign or malignant orbital masses in childhood. As early as 1908 Natanson $^{7}$ and later von Szily ${ }^{21}$ had recognised the pathogenesis of this disorder. Further studies by Badtke and Tost ${ }^{22}$ in laboratory animals showed the pathoanatomical features of these defects.

A number of authors have given their theories on the pathogenesis. According to $\mathrm{Mann}^{23}$ the normal optic vesicle tends to invaginate prior to the 6-7th embryonal week. During this period colobomatous cysts develop. The fetal fissures start to close usually at the $11 \mathrm{~mm}$ stage and closure is complete by the $18 \mathrm{~mm}$ stage. Since the inner layer of the optic cup develops faster, a slight eversion along the margins of the fissure is produced. If there is fully formed retina at the margins of the fissure, this prevents closure of the optic cup. If closure fails, a typical coloboma without overlying retina develops. In cases where no closure takes place, the edges of the retinal layers may further distend, fluid separates the two retinal layers, and a cyst forms. Finally the two separate cystic layers coming from the nasal and temporal side of the coloboma will blend into one large cyst. The fact that the cyst enlarged with time is probably due to excess fluid production by the glial cells. One argument for this is that the glial cells lining the orbital cyst inner surface show pronounced formation of microvilli. The cyst fluid might be produced by the glial tissue. In some cases a communication between the cyst and the subarachnoidal space has been thought to be responsible for continuous cyst enlargement. In most cases, however, no true communication could be demonstrated. Another mechanism for progressive enlargement of the cyst is extensive proliferation of glial tissue, eventually filling and expanding the cyst cavity. ${ }^{24}$ In most cases, however, no communication could be demonstrated despite enlargement of the cyst.

Immunohistochemistry using stains for GFAP demonstrates nicely the glial nature of the cyst wall, composed mainly of astrocytes. Stains for neurofilaments make it possible to identify a bundle of optic nerve axons. Modern methods of immunohistochemistry and scanning and transmission microscopy are valuable tools in addition to older histological techniques for studying congenital malformations of the eye and orbit.

We are grateful to Professor Dr B Daicker from the Ophthalmopathologic Laboratory of the University Eye Hospital in Basel for valuable advice and support in performing macroscopic sections and scanning electron microscopy. The scanning EM sections were made in the REM Lab of the University Basel (Professor Dr Guggenheim). We thank Professor Dr M Tost, of the University Eye Hospital, Halle (GDR), for reviewing the slides and giving us his expert opinion on this case.

1 Arstikaitis M. A case report of bilateral microphthalmos with cyst. Arch Ophthalmol 1969; 82: 480-2.

2 Badtke G, Tost $M$. Die Missbildungen des menschlichen Auges. In: Velhagen $\mathrm{K}$, ed. Der Augenarzt. Leipzig: Thieme, 1986: 11

3 Bonner J, Ide $\mathrm{CH}$. Astrocytoma of the optic nerve and chiasm associated with microphthalmos and orbital cyst. $\mathrm{Br} \mathcal{F}$ Ophthalmol 1974; 58: 828-31.

4 Briggs RM, Chase RA, Dellaporta A. Unilateral congenital orbital cyst with microphthalmos. Plast Reconstr Surg 1986; 41: $376-80$.

5 Hall D. Hyperplastic primary vitreous with microphthalmos and ocular communicating orbital cyst. Ann Ophthalmol and ocular comm

6 Jensen OA. Microphthalmia with associated pseudogliomatosis of the retina and pseudogliomatous orbital cyst. Acta Ophthalmol (Kbh) 1965; 43: 240-4.

7 Natanson L. Uber Mikrophthalmus and Anophthalmus congenitus mit serösen Orbitopalpebral-Zysten. Graefes Arch Clin Exp Ophthalmol 1908; 67: 185-271.

8 Schmitt H, Stärk N. Klinische und histologische Befunde einer retinalen Orbitazyste mit Mikrophthalmus. Klin Monatsbl Augenheilkd 1981; 179: 359-61.

9 Sherman J, Bass SJ, George A, Noble KG, Nath S. Optic pit, microphthalmos and orbital cyst. Ophthalmic Paedr Gene 1988; 9: 131-3.

10 Kok van Alpen DD, Manschot WA, Frederiks E, Beuseko van GT. Microphthalmos and orbital cyst. Ophthalmologica 1973; 167: 389-92.

11 Meyer E, Zonis S, Gdal-On M. Microphthalmos with orbital cyst. A clinocopathological report. $\mathcal{F}$ Pediatr Ophthalmol cyst. A clinocopathologica

12 Duke-Elder S. Normal and abnormal development: congenital deformities. System of ophthalmology. St Louis: Mosby, $1964 ; 3(2): 456-87$

13 Shields JA. Diagnosis and management of orbital tumors. Philadelphia: Saunders, 1989: 89-122.

14 Makley TA Jr, Battles M. Microphthalmos with cyst. Report of two cases in the same family. Suv Ophthalmol 1969; 13: $200-6$.

15 Wright DC, Yuh WTC, Thompson HS, Nerad JA. Bilateral microphthalmos with orbital cysts: MR findings. F Comput Assist Tomogr 1987; 11: 727-9.

16 Fisher Y. Microphthalmos with ocular communicating orbital cyst: ultrasonic diagnosis. Ophthalmology 1978; 85: 1208-11.

17 Weiss A, Martinez C, Greenwald M. Microphthalmos with cyst: clinical presentations and computed tomographic findings. F Pediatr Ophthalmol Strabismus 1985; 22:6-12.

18 Küchle HJ, Normann G, Lübbering J. Ein Beitrag zum kongenitalen Zystenauge. Klin Monatsbl Augenheilkd 1986; 188: $239-41$

19 Soares EJ, Lopes KD, Andrade JD, et al. Orbital malignant teratoma. A case report. Orbit 1983; 2: 235-42.

20 Waring G, Roth AM, Rodrigues MM. Clinicopathologic correlation of microphthalmos with cysts. Am $\mathcal{f}$ Ophthalmol 1976;82: 714-21.

21 Szily von A. Die Ontogenese der idiotypischen Spaltbildungen des Auges, des Mikrophthalmus und der Orbitalzysten. des Auges, des Mikrophthalmus und

22 Tost $M$. On a rare form of hyperplasia of the inner optic cup appearing as orbital cyst in hereditary microphthalmus in appearing as orbital cyst in hereditary microphthal
the mouse. Acta Ophthalmol $(K b h) 1966 ; 44: 568-76$.

23 Mann I. Developmental abnormalities of the eye. 2nd ed. Philadelphia: Lippincott, 1957: 66-9.

24 Nowinski T, Shields JA, Augsburger JJ, De Venuto JJ Exophthalmos secondary to massive intraocular gliosis in a patient with colobomatous cyst. Am $\mathcal{F}$ Ophthalmol 1984; 97 641-3. 